\title{
Maternal Separation Does Not Produce a Significant Behavioral Change in Mice
}

\author{
Shawn $\operatorname{Tan}^{1,2 \dagger}$, Hin San $\mathrm{Ho}^{1,2 \dagger}$, Anna Yoonsu Song ${ }^{1,3}$, Joey Low ${ }^{1,4}$ and Hyunsoo Shawn $\mathrm{Je}^{1,2 *}$ \\ ${ }^{1}$ Molecular Neurophysiology Laboratory, Signature Program in Neuroscience and Behavioral Disorders, \\ Duke-NUS Medical School, Singapore, 169857, \\ ${ }^{2}$ Department of Physiology, Yong Loo Lin School of Medicine, National University of Singapore, Singapore, 117597, \\ ${ }^{3}$ College of Liberal Studies, Seoul National University, Seoul 08826, Korea, \\ ${ }^{4}$ School of Biological Sciences, Nanyang Technological University, Singapore, 637551
}

Early life adversities together with genetic predispositions have been associated with elevated risks of neuropsychiatric disorders during later life. In order to investigate the underlying mechanisms, many chronic, early-life stress paradigms in multiple animal models have been developed. Previously, studies reported that maternal separation (MS) in the early postnatal stages triggers depression- and/or anxiety-like behaviors in rats. However, similar studies using mice have reported inconsistent behavioral outcomes. In this study, we sought to assess behavioral outcomes from two different early-life stress paradigms; a conventional 3-hour MS and a maternal separation with early weaning (MSEW) paradigm using C57BL/6J male mice with independent cohorts. Our data demonstrated that both MS and MSEW paradigms did not produce reported behavioral anomalies. Therefore, MS paradigms in mice require further validation and modification.

Key words: Early-life stress, Maternal separation, Maternal separation with early weaning, Depression, Anxiety, Emotional memories

\section{INTRODUCTION}

Early-life aversive experiences including childhood abuse, trauma, and neglect have been associated with increased risk for neuropsychiatric disorders, accompanied by potential neurophysiological changes such as the reduced volume and abnormal activation in the hippocampus, amygdala, and prefrontal cortex [1-5]. To identify underlying mechanisms of early-life, stress-induced brain dysfunction, maternal separation (MS) paradigms were developed

Received November 20,2017, Revised December 7,2017,

Accepted December 8, 2017

\footnotetext{
* To whom correspondence should be addressed.

TEL: 65-6601-1260, FAX: 65-6557-0729

e-mail: shawn.je@duke-nus.edu.sg

"These authors contributed equally to this work.
}

in rodents $[6,7]$. In typical maternal separation paradigms, pups undergo 3 hours or more episodes of separation from the dam daily, which has been linked to increased levels of stress hormones and behavioral changes in adult animals $[8,9]$. While maternal separation paradigms in rat models are relatively well-established, behavioral effects upon MS paradigms in mice are often inconsistent (Table 1) [10,11], which may be due to subtle differences among separation paradigms, animal handling, or housing environments.

Here, we employed two different, early-life stress paradigms - a conventional protocol with 3-hour separation from P2 to P14 (MS) and a relatively recent protocol with longer time for maternal separation together with early weaning at P17 (MSEW) in C57BL/6J mice [12]. Following the two different paradigms, animals underwent multiple behavioral tests relevant to depression-like and
Copyright ( Experimental Neurobiology 2017.

www.enjournal.org
This is an Open Access article distributed under the terms of the Creative Commons Attribution Non-Commercial License (http://creativecommons.org/licenses/by-nc/4.0) which permits unrestricted non-commercial use, distribution, and reproduction in any medium, provided the original work is properly cited. 
Table 1. Summary of some commonly used maternal separation paradigms and behavioral effects in adult male mice on emotion-related behaviors

\begin{tabular}{|c|c|c|c|}
\hline Strains & $\begin{array}{l}\text { Maternal separation } \\
\text { paradigm }\end{array}$ & $\begin{array}{c}\text { Behavioral phenotype in MS group in adulthood } \\
\text { (compared to controls) }\end{array}$ & Reference \\
\hline $\mathrm{C} 57 \mathrm{BL} / 6 \mathrm{~J}$ & 3 hours MS on P1-P9 & Elevated anxiety-like behavior in EPM and OF. & {$[14]$} \\
\hline CD-1 & 3 hours MS on P2-P14 & Decreased anxiety-like behavior in EPM. & {$[15]$} \\
\hline CD-1 & 24 hour MS on P12 & $\begin{array}{l}\text { No changes in locomotor activity in OF. No change in total time spent im- } \\
\text { mobile in FST. }\end{array}$ & [16] \\
\hline C57BLl/6NCrlBR & 3 hours MS on $\mathrm{P} 0-\mathrm{P9}$ & No changes in anxiety-related behavior in DWT. & {$[17]$} \\
\hline $\mathrm{C} 57 \mathrm{BL} / 6 \mathrm{~J}$ & 3 hours MS on P1-P10 & $\begin{array}{l}\text { No change in DWT. Decreased anxiety-like behavior in dark phase EZM } \\
\text { but increased anxiety in EPM. }\end{array}$ & {$[18]$} \\
\hline $\begin{array}{l}\text { 129S1, BALB/cByJ, C57BL/6J, } \\
\text { DBA/2J,FVB/NJ }\end{array}$ & 3 hours MS on $\mathrm{P} 0-13$ & $\begin{array}{l}\text { No overall changes in anxiety and depressive-related behavior in EPM, } \\
\text { LDB, OF and FST. }\end{array}$ & {$[10]$} \\
\hline $\mathrm{C} 57 \mathrm{BL} / 6 \mathrm{~J}$ & 24 hours MS on P9 & No change in OF activity. Decreased anxiety in EPM. & [19] \\
\hline $\mathrm{C} 57 \mathrm{BL} / 6 \mathrm{~J}$ & 3 hour MS on $\mathrm{P} 1-14$ & Increased anxiety in EPM but no change in anxiety behavior in $\mathrm{OF}$. & {$[20]$} \\
\hline $\mathrm{C} 57 \mathrm{BL} / 6 \mathrm{~J}$ and $\mathrm{BALB} / \mathrm{c}$ & 3 hours MS on P1-14 & No change in depressive-like behavior in FST. & [21] \\
\hline $\mathrm{C} 57 \mathrm{BL} / 6 \mathrm{~J}$ and $\mathrm{DBA} / 2 \mathrm{~J}$ & 24 hour MS on P9 & $\begin{array}{l}\text { Lowered anxiety-related behavior in OF. No changes in hole board explor- } \\
\text { atory activity. No change in depressive-like behavior in FST. }\end{array}$ & {$[22]$} \\
\hline $\mathrm{C} 57 \mathrm{BL} / 6 \mathrm{~J}$ & 3 hours MS on P2-14 & $\begin{array}{l}\text { No change in LDB anxiety-related behavior. NSF behavior not affected. } \\
\text { Decreased anxiety-like behavior in OF in last } 15 \text { minutes. No change in } \\
\text { depressive-like behavior in FST. }\end{array}$ & [23] \\
\hline CCR7 deficient C57BL/6J & 3 hours MS on P1-14 & $\begin{array}{l}\text { No change in anxiety-like behavior in OF and EZM. No change in depres- } \\
\text { sive-like behavior in saccharin preference test. }\end{array}$ & {$[24]$} \\
\hline
\end{tabular}

MS, maternal separation; EPM, Elevated Plus Maze; EZM, Elevated Zero Maze; FST, Forced Swim Test; OF, Open field; DWT, Defensive withdrawal test; LDB, Light/dark box; NSF, Novelty suppressed feeding.

anxiety-like behaviors and cognitive functions at P60. We hypothesized that the MSEW paradigm would result in increased severity in anxiety- and depressive-like behavior as well as enhanced contextual and cue fear learning as reported $[12,13]$. Intriguingly, we could not observe the predicted behavioral anomalies upon either MS or MSEW paradigm.

\section{MATERIALS AND METHODS}

\section{Animals}

C57BL/6J breeding pairs were housed in a specific pathogen-free environment and maintained at $22^{\circ} \mathrm{C}$ with $55 \%$ humidity. Food and water were provided ad libitum on a 12-hr light/dark cycle (lights on at $0700 \mathrm{~h}$ ). Breeding pairs were checked daily for litters. If birth occurred, age was designated as P0. All the pups from one dam (a litter) were randomly assigned to one of the groups. Upon weaning, littermates were group-housed (up to 4 per cage). All experimental procedures were conducted in accordance with guidelines for the care and use of laboratory animals for scientific purposes with approved protocols from the Institutional Animal Care and Use Committees of Duke-NUS Medical School (Protocol number: 2014/SHS/999). All tests were conducted on the same co- horts of animals. The MS cohort originally consisted of 9 MS and $8 \mathrm{MC}$ mice while the MSEW cohort was comprised of 9 MSEW mice and $12 \mathrm{MC}$ mice. During the course of testing, one cage in the MC group in the MSEW cohort exhibited excessive fighting and three mice progressively sustained severe injuries and were excluded from some tests. Other exclusions are listed in the figure legends.

\section{Maternal separation procedures}

In the maternal control (MC) group, with the exception of routine bi-weekly cage changes, pups were left untouched with the dams until weaning at P21. For both maternal separation procedures, dams were moved from home cages to a clean cage with ad libitum food and water during separation. Additionally, cages containing the dams were placed in a separate room to prevent any potential communication among the dams and pups. At the end of the separation period, both pups and dams were returned to the home cage.

\section{Maternal separation (MS)}

In the maternal separation group (MS), pups were removed from their home cages from P2 to P14 for 3 hours daily at randomized 
time points during the light cycle $[10,23]$. From P2 to 7, pups were placed together on a heating pad maintained at $37^{\circ} \mathrm{C}$ during the separation period. From P7 to 14, pups were placed onto separate containers individually without heating. Pups were weaned at P21.

\section{Maternal separation with early weaning (MSEW)}

MSEW procedure was conducted as described previously [12, 25]. Briefly, pups were removed from their home cages from P2 to 5 for 4 hours per day at randomized time points during the light cycle and placed together on a heating pad maintained at $37^{\circ} \mathrm{C}$. From P6 to 16, pups were removed from the dams for 8 hours daily and placed into separate containers individually without heating. Pups were weaned at P17.

\section{Behavioral testing of offspring}

At P60, male mice were subjected to behavioral tests in the order listed below. Behavioral tests were only conducted in males.

\section{Open field}

The open field test was conducted in an arena measuring 40 $\mathrm{cm}$ by $40 \mathrm{~cm}$ by $30 \mathrm{~cm}$ in height using an automated VersaMax Animal Activity Monitor and VersaMax software v.4.12-1AFE (AccuScan Instruments, Columbus, Ohio) under 400 lux illumination during the light phase (1200 1900). To capture the general locomotor activity of mice under non-aversive condition, the open field test was also conducted during the dark phase (2000 0000) under low illumination ( $<10$ lux). Mice were put onto the center of the arena for 60-min testing and baseline locomotor activity was automatically recorded. Locomotion was measured as total distance traveled and stereotypy was measured as the number of consecutive beam breaks ( $<1$ second).

\section{Light/dark box}

A red acrylic enclosure was inserted to divide the open field chamber into equal light and dark compartments for the light/ dark box test. The light $\left(40 \times 20 \times 30 \mathrm{~cm}^{3}, \sim 400\right.$ lux $)$ and dark $\left(40 \times 20 \times 30 \mathrm{~cm}^{3}, \sim 60\right.$ lux $)$ compartments were connected via an opening $\left(5 \times 5 \mathrm{~cm}^{2}\right)$ allowing transitions between both compartments. During the 10-min test, the percent of time an animal spent in the light compartment and locomotor activity were recorded using the VersaMax software. In addition, the number of transitions between the compartments was scored manually.

\section{Tail suspension}

The tail suspension test was performed to measure depressionlike behavior by using the Tail Suspension Test Cubicle, PHM-300 (Med Associates, USA). Each mouse was suspended to a hook that was $20 \mathrm{~cm}$ above the ground with an adhesive tape for $6 \mathrm{~min}$. Two animals were tested at the same time and separated by partitions to avoid potential communication between each other. Their overall movement was recorded using Tail Suspension Software, v.3.4.1.0 (Med Associates, Georgia, Vermont, USA) and activity thresholds were adjusted to detect immobility.

\section{Forced swim test}

The forced swim test was conducted using methods previously described [26]. Each mouse was gently placed in a custom-made cylinder (height, $40 \mathrm{~cm}$; diameter, $20 \mathrm{~cm}$ ) containing $13 \mathrm{~cm}$ of water at room temperature for $6 \mathrm{~min}$ and then returned to the home cage. Twenty-four hours later, the mouse was retested for $6 \mathrm{~min}$. A professional video camcorder (Canon, Japan) was used to record trials for further analysis. Immobility time was scored using the Topscan Realtime Option software, v3.00 (Clever Sys, Inc., USA). A mouse was judged immobile when it ceased any movements except those that were necessary to keep its head above water. Immobility time is expressed as a percentage of the total time measurement.

\section{Contextual and cued fear conditioning}

Fear conditioning was conducted using the Fear Conditioning System, MED-VFC2-NIR-M (MedAssociates, USA). Mice were habituated to the chamber for two minutes. For the fear conditioning procedure, a 30-s tone (CS: $90 \mathrm{~dB} 10 \mathrm{kHz}$ white noise or sine wave) was presented that co-terminated with an electric foot shock (US: $2 \mathrm{~s}, 1.0 \mathrm{~mA}$ ). The conditioning procedure was repeated twice with inter-tone intervals of $2 \mathrm{~min}$. Animals were returned to their home cages about 1 min after the last foot shock. 24 hours later, mice were tested for contextual and cued fear. For contextual fear memory recall, mice were replaced in the conditioning chamber for 5 min without any tone or foot shock, and then removed afterwards. To test cued fear memory, mice were placed into the original chamber that was redecorated to alter the visual cues, illumination and texture. The grills on the floor were covered with a white board, a red filter was placed over the overhead lamp, and the plain walls were covered with wallpaper of geometric patterns. Two min later, the CS was presented for 2 minutes. Mice were returned to home cages $1 \mathrm{~min}$ after termination of tone presentation.

In the fear conditioning experiments, the activity of animals was measured using Video Freeze Software, v 1.20.5.0 (MedAssociates, USA). Freezing responses to the conditioned context and tones were analyzed and expressed as total number of episodes and percentage of the observation time (freezing [\%]=freezing time/ observation time $\times 100 \%$ ). 


\section{Statistical analyses}

Data were analyzed and plotted using GraphPad Prism (Graphpad Software, San Diego, California, USA) and presented as mean \pm SEM. Unless otherwise stated, data were analyzed by unpaired t-test. Measures on tail suspension, forced swim and open field tests across time was performed by Two-Way ANOVA with repeated measures followed by Tukey's honest significance test. A $p<0.05$ was accepted as statistically significant. In addition, extreme values were subjected to Grubb's test for outliers (http:// graphpad.com/quickcalcs/Grubbs1.cfm) and excluded from analysis.

\section{RESULTS}

\section{MS and MSEW effects on depressive-like behaviors}

\section{Tail suspension}

Either MS or MSEW was carried out on separate batches of animals, with separate groups of control mice (MC) from littermate dams. There was no significant effect of either MS or MSEW paradigm on the stationary time in the tail suspension test (Fig. $1 \mathrm{~A}$ and B). A two-way ANOVA with repeated measures showed no significant interaction between treatment conditions and time upon either MS $\left(\mathrm{F}_{(5,65)}=0.412, \mathrm{p}=0.839\right)$ or $\operatorname{MSEW}\left(\mathrm{F}_{(5,75)}=1.916\right.$, $\mathrm{p}=0.102$ ). There was no main effect of treatment condition, given that the stationary time was not significantly different between MS and $\mathrm{MC}$ mice $\left(\mathrm{F}_{(1,13)}=0.507, \mathrm{p}=0.489\right)$, and between MSEW and
A

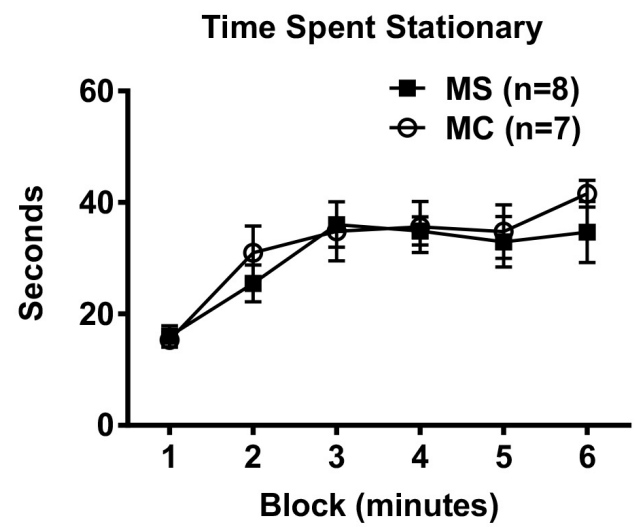

C

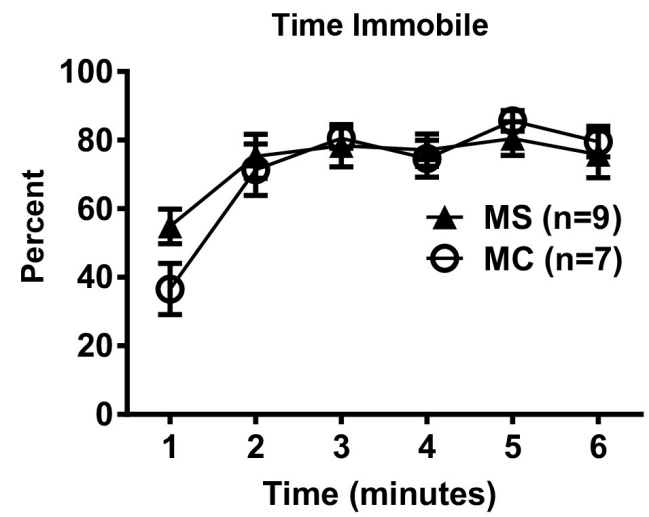

B

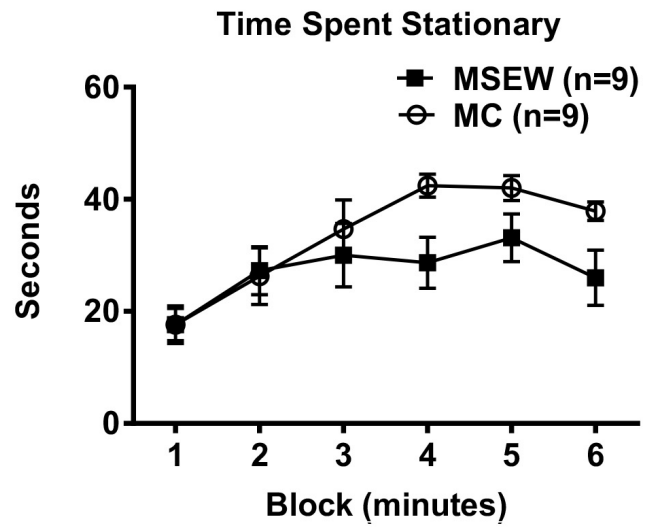

D

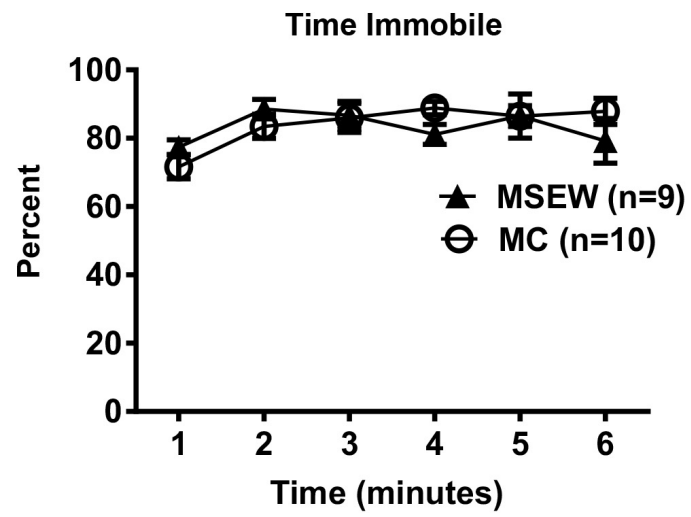

Fig. 1. MS and MSEW mice did not exhibit depression-related behavior compared to controls. There was no significant difference in the time spent stationary on the tail suspension test between (A) MS mice and MC mice and (B) MSEW and MC mice. One mouse from each group in the MS cohort was excluded for excessive climbing and three mice from the MC group in the MSEW cohort were excluded for severe injuries. There was no significant difference in the immobility time during the second trial of a forced swim test between (C) MS and MC mice and (D) MSEW and MC mice. One mouse in the MS cohort was excluded for excessive hyperactivity and two mice in the MC group in the MSEW cohort were excluded for severe injuries. All values are means \pm SEM. 
controls $\left(\mathrm{F}_{(1,15)}=2.574, \mathrm{p}=0.130\right)$.

\section{Forced swim test}

Either MS or MSEW paradigm did not induce any significant effect on immobility time during the test trial of the forced swim test (Fig. 1C and D). A two-way ANOVA with repeated measures revealed no interaction between treatment condition and time for the MS $\left(\mathrm{F}_{(5,84)}=1.134, \mathrm{p}=0.349\right)$ as well as $\operatorname{MSEW}\left(\mathrm{F}_{(5,102)}=1.208\right.$, $\mathrm{p}=0.311)$ cohorts. The main effects of treatment condition for both $\operatorname{MS}\left(\mathrm{F}_{(1,84)}=0.469, \mathrm{p}=0.495\right)$ and $\operatorname{MSEW}\left(\mathrm{F}_{(1,102)}=0.125, \mathrm{p}=0.725\right)$ were not statistically significant. Taken together, these data indicated that either MS or MSEW paradigm did not produce any salient effects on the depressive-like behavior.

A



E


C



G
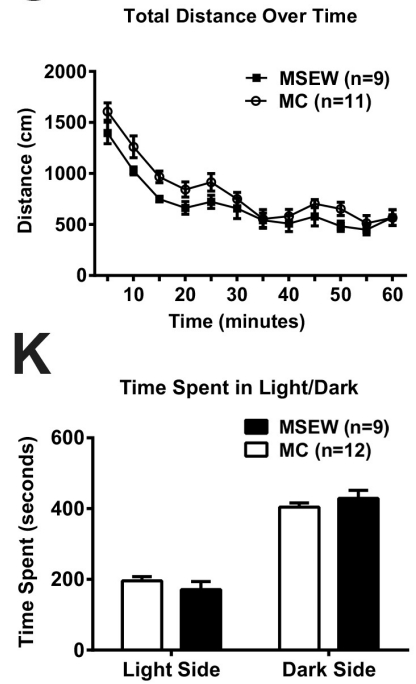

MS and MSEW effects on general locomotor activity and anxiety-like behavior

We tested animals in the open field for 60 minutes to measure the general locomotor activity. Distance traveled in the open field was defined as a general measure for horizontal activity. Time spent in the center zone was also measured as an index of anxietylike behavior.

\section{Open field (light phase)}

During the open field exposure during light phase (approximately 400 lux), MS and MSEW conditions produced no difference in the distance traveled (Fig. 2A and C). A two-way ANOVA with repeated measures indicated no interaction between MS

Fig. 2. MS and MSEW mice show changes in locomotor activity in the open field during the dark phase but did not display anxiety-like behavior compared to controls. In the open field conducted during the light phase, there were no significant differences on distance traveled over time between (A) MS and MC group and (C) MSEW and MC group. On the time spent in the center zone, which can be interpreted as an anxiety-related behavior, there were no significant differences between (B) MS and MC group and (D) MSEW and MC group. Two mice from the MC group in the MSEW cohort were excluded for severe injuries. In the open field conducted during the dark phase (E) MS mice traveled significantly more than controls during the 30, 35 , 40 and $60 \mathrm{~min}(\mathrm{p}<0.01)$ and $(\mathrm{G})$ MSEW traveled significantly less over time compared to $\mathrm{MC}(\mathrm{p}<0.05)$, but post-hoc tests were not significant. There were no differences in the time spent in center of the open field between (F) MS and MC and (H) MSEW and MC mice during the dark phase. One mouse from the MC group in the MS cohort was excluded for as an outlier for excessive hyperactivity and one mouse from the MC group in the MSEW cohort was excluded for severe injuries. In the light/dark box test, there were no significant differences in the time spent in light and dark compartments as well as the number of transitions between both compartments between (I and K) MS and MC mice and (J and L) MSEW and MC mice. ${ }^{\star}$ Indicates $\mathrm{p}<0.01$ for the post-hoc test for that particular time bin. All values are means \pm SEM. 
and time $\left(\mathrm{F}_{(11,231)}=1.81, \mathrm{p}=0.0528\right)$ and between MSEW and time $\left(\mathrm{F}_{(11,187)}=0.591, \mathrm{p}=0.835\right)$. Either MS or MSEW did not produce any effect on the total distance traveled $\left(\mathrm{F}_{(1,21)}=0.0515, \mathrm{p}=0.823\right)$ and $\left(\mathrm{F}_{(1,17)}=0.312, \mathrm{p}=0.584\right)$, respectively. With regards to anxiety-like behavior, MS and MSEW conditions had no significant effect with respect to the center duration in the open field (Fig. 2B and D). T- tests were performed on the time spent in the center and revealed no significant difference between MS ( $\mathrm{p}=0.511)$, MSEW ( $\mathrm{p}=0.488$ ) compared to MC groups.

\section{Open field (dark phase)}

Interestingly, either MS or MSEW resulted in significant ef-
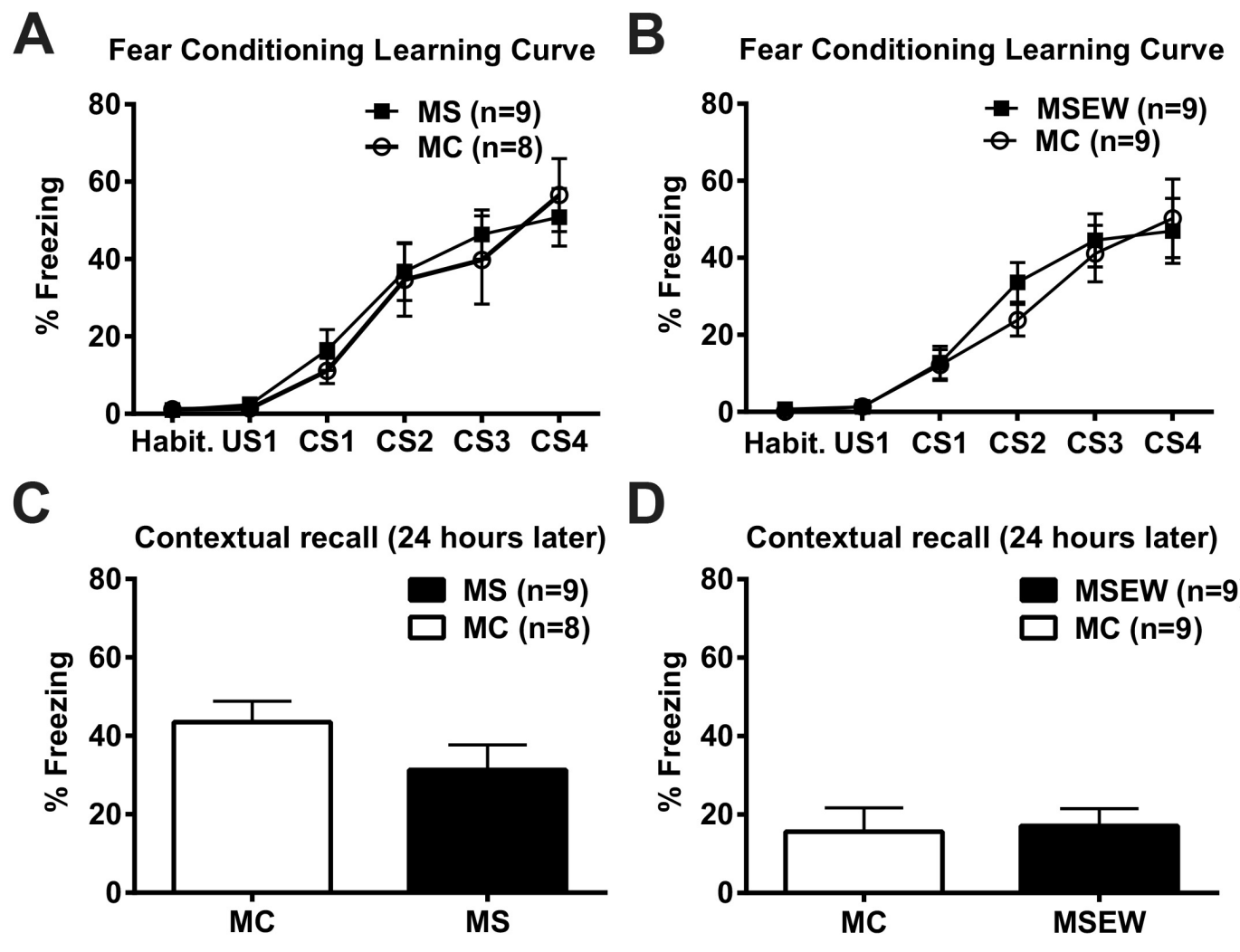

E

Cue recall (24 hours later)

$\mathbf{F}$
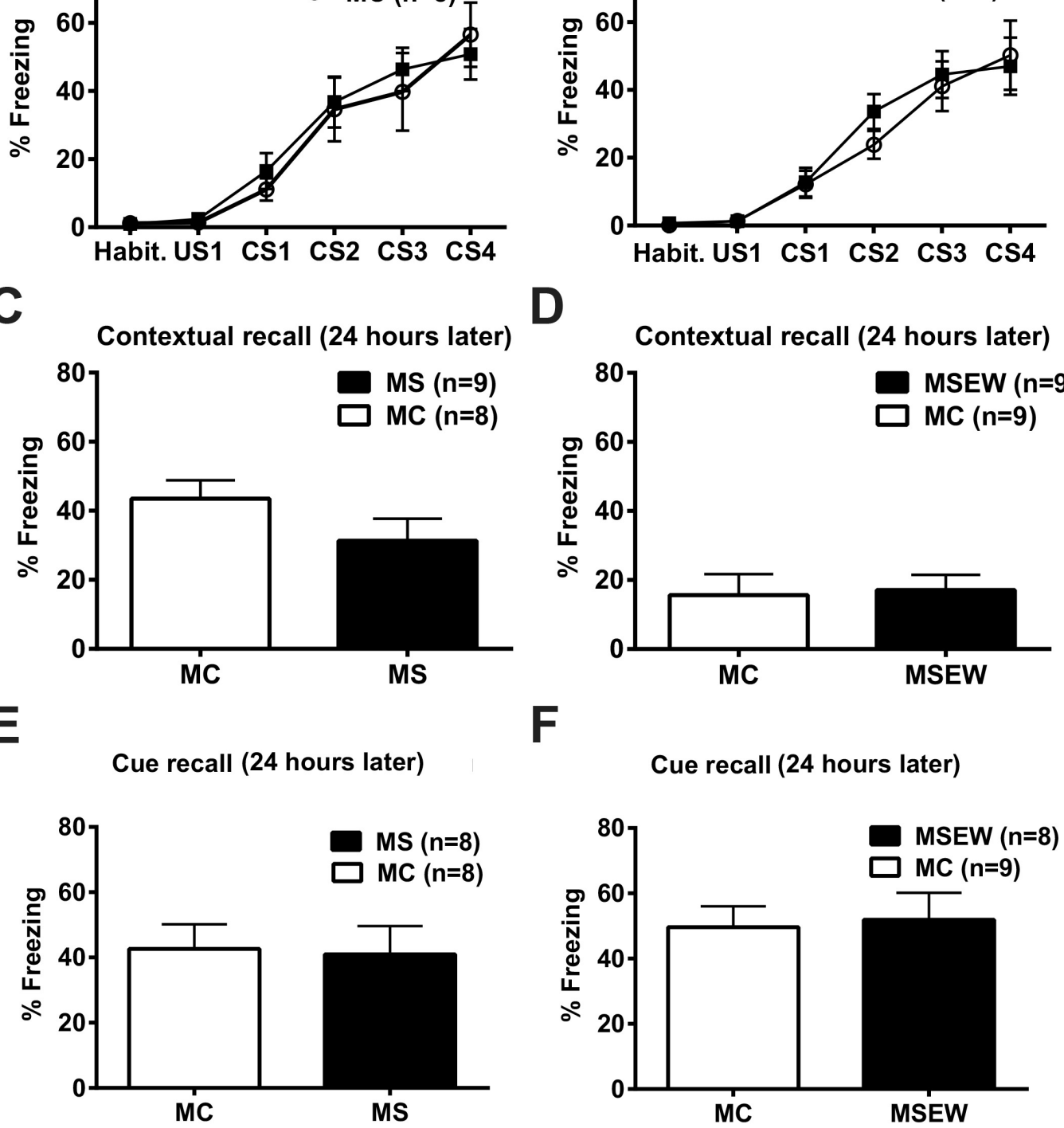

Fig. 3. Mice which experienced MS or MSEW did not exhibit impairments in hippocampal and amygdala-dependent fear-related emotional memories. In the acquisition phase of the fear conditioning test, there were no significant difference between (A) MS and MC mice and (B) MSEW and MC mice in the percent freezing time when exposed to the conditioned stimulus (tone) paired with the unconditioned stimulus (foot shock). Habit, Habituation; US, Unconditioned Stimulus; CS, Conditioned Stimulus. Three mice from the MC group in the MSEW cohort were excluded for severe injuries. During the contextual fear recall 24 hours after training, there were no significant differences between (C) MS and MC mice and (D) MSEW and MC mice on percent freezing time. During the cue fear recall 24 hours after training, there was also no significant differences between (E) MS and MC mice and (F) MSEW and MC mice on percent freezing time. One mice from MS and MSEW group were each excluded as outliers for low freezing responses. All values are means \pm SEM. 
fects on general locomotor activity in an one-hour open-field test. Statistical analyses indicated no interaction between MS and time $\left(\mathrm{F}_{(11,154)}=0.382, \mathrm{p}=0.961\right)$ and between MSEW and time $\left(F_{(11,198)}=0.778, p=0.662\right)$, but there was a main effect of treatment condition; $\mathrm{MS}$ treated mice $\left(\mathrm{F}_{(1,14)}=12.4, \mathrm{p}=0.0034\right)$ traveled more distance over time, while MSEW treated mice $\left(\mathrm{F}_{(1,18)}=4.94\right.$, $\mathrm{p}=0.0393$ ) traveled less (Fig. 2E and G). A post-hoc analysis indicated that MS mice traveled significantly more than the MC group during the $30(\mathrm{p}=0.000517), 35(\mathrm{p}=0.00111), 40(\mathrm{p}=0.000796)$, and 60 minutes $(\mathrm{p}=0.00028)$ during the open-field test, indicating slight hyperactivity of animals. With regards to anxiety-like behavior, MS and MSEW conditions had no significant effect with respect to the center duration in the open field (Fig. $2 \mathrm{~F}$ and $\mathrm{H}$ ). T-tests indicated no difference in the time spent in the center for MS ( $\mathrm{p}=0.517)$ and MSEW $(\mathrm{p}=0.360)$ compared to their respective control groups.

\section{Light/dark box}

MS and MSEW conditions did not elicit any significant effect on the time spent in either the light or dark compartments (Fig. 2I and K). A multiple t-test indicated no significant difference between the time spent in either the light or dark compartments for MS ( $\mathrm{p}=0.721$ ) or MSEW ( $\mathrm{p}=0.318$ ) mice, compared to the MC groups during the first 10 minutes. There was no significant difference in the number of transitions between MS ( $p=0.845)$ and MSEW ( $p=0.222$ ), compared to MC groups (Fig. 2J and L). This indicates that both batches of MS and MSEW mice did not exhibit an increased anxiety-like phenotype in the light/dark box test.

\section{MS and MSEW effects on acquisition and retention of fear memory}

Either MS or MSEW condition did not produce any significant effects on the percentage of time spent freezing during the first day of a training phase in the fear-conditioning assay (Fig. 3A and B). Freezing behavior is the absence of any movement except for respiration and is used as an index for fear conditioning. A twoway ANOVA with repeated measures indicated no interaction between MS and trials $\left(\mathrm{F}_{(5,75)}=0.307, \mathrm{p}=0.907\right)$ and between MSEW and trials $\left(\mathrm{F}_{(5,80)}=0.451, \mathrm{p}=0.811\right)$. MS $\left(\mathrm{F}_{(1,15)}=0.0830, \mathrm{p}=0.777\right)$ and $\operatorname{MSEW}\left(\mathrm{F}_{(1,16)}=0.153, \mathrm{p}=0.701\right)$ produced no effect on the percentage freezing time. This indicates that MS and MSEW mice were not impaired in acquiring emotional memories compared to the MC groups.

On the Day 2 of the fear-conditioning assay, MS and MSEW also did not produce significant effect on the percentage freezing time during the contextual and cued recall sessions. During the contextual recall session, there was no significant difference in the percentage freezing time between MS ( $\mathrm{p}=0.169)$, compared to MC group, and MSEW ( $\mathrm{p}=0.847$ ), compared to MC group (Fig. $3 \mathrm{C}$ and $\mathrm{D})$. In addition, no significant difference was found in the percentage freezing time between MS ( $\mathrm{p}=0.888)$ and MC group and between MSEW ( $\mathrm{p}=0.827$ ) and MC group during the cued recall session (Fig. 3E and F). These data suggested that mice which experienced either MS or MSEW did not exhibit any significant impairment in fear memory consolidation and retention.

\section{DISCUSSION}

We sought to identify an early-life stress paradigm that could exert long-lasting and reproducible changes in animal behavior and stress reactivity to investigate a potential environmental trigger in the pathophysiology of neuropsychiatric disorders such as anxiety, depression, and schizophrenia $[27,28]$. The conventional 3-hour, MS paradigm was compared with a relatively new MSEW paradigm to determine which paradigm could be more effective in altering emotionality and increasing stress reactivity in adulthood. To our surprise, however, we observed that both MS and MSEW paradigms did not elicit any significant behavioral changes in depressive-like behavior and anxiety-like behavior (Fig. 1 and 2) as well as fear memory acquisition or recall in both the contextual and cue fear test (Fig. 3). The only difference we could observe was that mice which underwent MS paradigm traveled significantly further distance than controls, while mice which underwent MSEW traveled significantly less in the open field test, both of which were not consistent with outcomes from previous studies $[10,21]$. Our lack of reproducibility in eliciting previously reported behavioral change in depressive- and anxiety-like behaviors upon MS are surprisingly consistent with previous reviews $[10,11]$. More intriguingly, the MSEW paradigm, which was reported to produce robust anxiety-like behavior, did not elicit any significant behavioral change in C57BL/6J male mice $[12,25]$.

One caveat is that the limited sample size of our groups may have resulted in insufficient power to detect significant effects [29]. In addition, factors such as the housing/experimental conditions and colony/sub-strain divergence may explain why our results differ from similar studies conducted with C57/BL6 mice [30-32] . Further studies are needed to assess if these results are replicable.

These lack of consistent phenotypes upon MS and MSEW paradigms may indicate the limited effectiveness of these paradigms in modeling an early life stress in mice, compared to other species such as rats or primates $[33,34]$. Instead, although we did not investigate in this study, early-life stress paradigms based on stressing dam and on additional early life stressors could be more effective. These paradigms are: reduced nesting material from P2-P9, which 
disrupts dam-pup interactions [35], social isolation of young animals following MS [36], and maternal stress in the form of tube restraints or forced swimming on dams [37]. Rather than focusing on modifying the duration of maternal separation, alterations to the early rearing environment or additional stressors may be a better alternative or inclusion in maternal separation paradigms.

Taken together, we observed no significant behavioral change upon either MS or MSEW paradigm on male mice. MSEW, which has been gaining popularity over MS recently, could not elicit previously reported results. Our results necessitate further replication studies and the optimization of a stress paradigm in mice to bring about long-lasting and reproducible behavioral changes. The development of such paradigms will be critical in investigating the causal relationship between early-life aversive experience and the pathophysiology of human psychiatric disorders.

\section{ACKNOWLEDGEMENTS}

We thank Dr. Yichun Yen and Ms. Audrey Khoo for her critical comments on the manuscript. This work was supported by Singapore Ministry of Education (MOE) academic research fund (MOE2014-T2-2-071) and Duke-NUS Signature Research Program Block Grant to H.S.J., and Khoo Postdoctoral Fellowship Award (Duke-NUS-KPFA/2017/0016) to S.T.

\section{REFERENCES}

1. Anda RF, Felitti VJ, Bremner JD, Walker JD, Whitfield C, Perry BD, Dube SR, Giles WH (2006) The enduring effects of abuse and related adverse experiences in childhood. A convergence of evidence from neurobiology and epidemiology. Eur Arch Psychiatry Clin Neurosci 256:174-186.

2. Fryers T, Brugha T (2013) Childhood determinants of adult psychiatric disorder. Clin Pract Epidemiol Ment Health 9:150.

3. Stein MB, Koverola C, Hanna C, Torchia MG, McClarty B (1997) Hippocampal volume in women victimized by childhood sexual abuse. Psychol Med 27:951-959.

4. Mathew SJ, Mao X, Coplan JD, Smith EL, Sackeim HA, Gorman JM, Shungu DC (2004) Dorsolateral prefrontal cortical pathology in generalized anxiety disorder: a proton magnetic resonance spectroscopic imaging study. Am J Psychiatry 161:1119-1121.

5. Malter Cohen M, Jing D, Yang RR, Tottenham N, Lee FS, Casey BJ (2013) Early-life stress has persistent effects on amygdala function and development in mice and humans. Proc Natl Acad Sci U S A 110:18274-18278.
6. Levine S (1956) A further study of infantile handling and adult avoidance learning. J Pers 25:70-80.

7. Hofer MA (1975) Studies on how early maternal separation produces behavioral change in young rats. Psychosom Med 37:245-264.

8. Newport DJ, Stowe ZN, Nemeroff CB (2002) Parental depression: animal models of an adverse life event. Am J Psychiatry 159:1265-1283.

9. Pryce CR, Bettschen D, Nanz-Bahr NI, Feldon J (2003) Comparison of the effects of early handling and early deprivation on conditioned stimulus, context, and spatial learning and memory in adult rats. Behav Neurosci 117:883-893.

10. Millstein RA, Holmes A (2007) Effects of repeated maternal separation on anxiety- and depression-related phenotypes in different mouse strains. Neurosci Biobehav Rev 31:3-17.

11. Tractenberg SG, Levandowski ML, de Azeredo LA, Orso R, Roithmann LG, Hoffmann ES, Brenhouse H, Grassi-Oliveira R (2016) An overview of maternal separation effects on behavioural outcomes in mice: evidence from a four-stage methodological systematic review. Neurosci Biobehav Rev 68:489-503.

12. George ED, Bordner KA, Elwafi HM, Simen AA (2010) Maternal separation with early weaning: a novel mouse model of early life neglect. BMC Neurosci 11:123.

13. Gracia-Rubio I, Moscoso-Castro M, Pozo OJ, Marcos J, Nadal $\mathrm{R}$, Valverde O (2016) Maternal separation induces neuroinflammation and long-lasting emotional alterations in mice. Prog Neuropsychopharmacol Biol Psychiatry 65:104-117.

14. Romeo RD, Mueller A, Sisti HM, Ogawa S, McEwen BS, Brake WG (2003) Anxiety and fear behaviors in adult male and female C57BL/6 mice are modulated by maternal separation. Horm Behav 43:561-567.

15. Venerosi A, Cirulli F, Capone F, Alleva E (2003) Prolonged perinatal AZT administration and early maternal separation: effects on social and emotional behaviour of periadolescent mice. Pharmacol Biochem Behav 74:671-681.

16. Macrì S, Laviola G (2004) Single episode of maternal deprivation and adult depressive profile in mice: interaction with cannabinoid exposure during adolescence. Behav Brain Res 154:231-238.

17. Parfitt DB, Levin JK, Saltstein KP, Klayman AS, Greer LM, Helmreich DL (2004) Differential early rearing environments can accentuate or attenuate the responses to stress in male C57BL/6 mice. Brain Res 1016:111-118.

18. Parfitt DB, Walton JR, Corriveau EA, Helmreich DL (2007) Early life stress effects on adult stress-induced corticosterone secretion and anxiety-like behavior in the C57BL/6 mouse 
are not as robust as initially thought. Horm Behav 52:417426.

19. Fabricius K, Wörtwein G, Pakkenberg B (2008) The impact of maternal separation on adult mouse behaviour and on the total neuron number in the mouse hippocampus. Brain Struct Funct 212:403-416.

20. van Heerden JH, Russell V, Korff A, Stein DJ, Illing N (2010) Evaluating the behavioural consequences of early maternal separation in adult C57BL/6 mice; the importance of time. Behav Brain Res 207:332-342.

21. Savignac HM, Dinan TG, Cryan JF (2011) Resistance to early-life stress in mice: effects of genetic background and stress duration. Front Behav Neurosci 5:13.

22. Kember RL, Dempster EL, Lee TH, Schalkwyk LC, Mill J, Fernandes C (2012) Maternal separation is associated with strain-specific responses to stress and epigenetic alterations to Nr3c1, Avp, and Nr4al in mouse. Brain Behav 2:455-467.

23. Own LS, Patel PD (2013) Maternal behavior and offspring resiliency to maternal separation in $\mathrm{C} 57 \mathrm{Bl} / 6$ mice. Horm Behav 63:411-417.

24. Harrison EL, Jaehne EJ, Jawahar MC, Corrigan F, Baune BT (2014) Maternal separation modifies behavioural and neuroendocrine responses to stress in CCR7 deficient mice. Behav Brain Res 263:169-175.

25. Carlyle BC, Duque A, Kitchen RR, Bordner KA, Coman D, Doolittle E, Papademetris X, Hyder F, Taylor JR, Simen AA (2012) Maternal separation with early weaning: a rodent model providing novel insights into neglect associated developmental deficits. Dev Psychopathol 24:1401-1416.

26. Porsolt RD, Le Pichon M, Jalfre M (1977) Depression: a new animal model sensitive to antidepressant treatments. Nature 266:730-732.

27. Bale TL, Baram TZ, Brown AS, Goldstein JM, Insel TR, McCarthy MM, Nemeroff CB, Reyes TM, Simerly RB, Susser ES, Nestler EJ (2010) Early life programming and neurodevelopmental disorders. Biol Psychiatry 68:314-319.

28. Pechtel P, Pizzagalli DA (2011) Effects of early life stress on cognitive and affective function: an integrated review of human literature. Psychopharmacology (Berl) 214:55-70.

29. Button KS, Ioannidis JP, Mokrysz C, Nosek BA, Flint J, Robinson ES, Munafò MR (2013) Power failure: why small sample size undermines the reliability of neuroscience. Nat Rev Neurosci 14:365-376.

30. Mitchell E, Klein SL, Argyropoulos KV, Sharma A, Chan RB, Toth JG, Barboza L, Bavley C, Bortolozzi A, Chen Q, Liu B, Ingenito J, Mark W, Dudakov J, Gross S, Di Paolo G, Artigas F, van den Brink M, Toth M (2016) Behavioural traits propagate across generations via segregated iterative-somatic and gametic epigenetic mechanisms. Nat Commun 7:11492.

31. Juetten J, Einat H (2012) Behavioral differences in black Swiss mice from separate colonies: implications for modeling domains of mania. Behav Pharmacol 23:211-214.

32. Bryant CD, Zhang NN, Sokoloff G, Fanselow MS, Ennes HS, Palmer AA, McRoberts JA (2008) Behavioral differences among C57BL/6 substrains: implications for transgenic and knockout studies. J Neurogenet 22:315-331.

33. Holmes A, le Guisquet AM, Vogel E, Millstein RA, Leman S, Belzung C (2005) Early life genetic, epigenetic and environmental factors shaping emotionality in rodents. Neurosci Biobehav Rev 29:1335-1346.

34. Pryce CR, Rüedi-Bettschen D, Dettling AC, Feldon J (2002) Early life stress: long-term physiological impact in rodents and primates. News Physiol Sci 17:150-155.

35. Rice CJ, Sandman CA, Lenjavi MR, Baram TZ (2008) A novel mouse model for acute and long-lasting consequences of early life stress. Endocrinology 149:4892-4900.

36. Niwa M, Matsumoto Y, Mouri A, Ozaki N, Nabeshima T (2011) Vulnerability in early life to changes in the rearing environment plays a crucial role in the aetiopathology of psychiatric disorders. Int J Neuropsychopharmacol 14:459-477.

37. Weiss IC, Franklin TB, Vizi S, Mansuy IM (2011) Inheritable effect of unpredictable maternal separation on behavioral responses in mice. Front Behav Neurosci 5:3. 